\title{
Clinical outcomes of chemoradiotherapy for locally recurrent rectal cancer
}

\author{
Joo Ho Lee ${ }^{1,2}$, Dae Yong Kim", Sun Young Kim¹, Ji Won Park', Hyo Seong Choi ${ }^{1}$, Jae Hwan Oh ${ }^{1}$, Hee Jin Chang ${ }^{1}$,
} Tae Hyun Kim ${ }^{1}$ and Suk Won Park ${ }^{3}$

\begin{abstract}
Background: To assess the clinical outcome of chemoradiotherapy with or without surgery for locally recurrent rectal cancer (LRRC) and to find useful and significant prognostic factors for a clinical situation.

Methods: Between January 2001 and February 2009, 67 LRRC patients, who entered into concurrent chemoradiotherapy with or without surgery, were reviewed retrospectively. Of the 67 patients, 45 were treated with chemoradiotherapy plus surgery, and the remaining 22 were treated with chemoradiotherapy alone. The mean radiation doses (biologically equivalent dose in 2-Gy fractions) were 54.6 Gy and 66.5 Gy for the chemoradiotherapy with and without surgery groups, respectively.

Results: The median survival duration of all patients was 59 months. Five-year overall (OS), relapse-free (RFS), locoregional relapse-free (LRFS), and distant metastasis-free survival (DMFS) were 48.9\%, 31.6\%, 66.4\%, and 40.6\%, respectively. A multivariate analysis demonstrated that the presence of symptoms was an independent prognostic factor influencing OS, RFS, LRFS, and DMFS. No statistically significant difference was found in OS $(p=0.181)$, RFS $(p=0.113)$, LRFS $(p=0.379)$, or DMFS ( $p=0.335)$ when comparing clinical outcomes between the chemoradiotherapy with and without surgery groups.

Conclusions: Chemoradiotherapy with or without surgery could be a potential option for an LRRC cure, and the symptoms related to LRRC were a significant prognostic factor predicting poor clinical outcome. The chemoradiotherapy scheme for LRRC patients should be adjusted to the possibility of resectability and risk of local failure to focus on local control.
\end{abstract}

\section{Background}

Recent advances in preoperative evaluation, treatment strategies and rectal cancer modalities have lead to better survival outcomes for patients with rectal cancer and a lower incidence of local recurrence [1,2]. Despite such improvements, $6-10 \%$ of patients with primary rectal cancer still experience intrapelvic local recurrence with or without distant metastasis [3-5]. These patients show a poor survival outcome with a nearly zero 5 -year survival and 3-12 months of median survival when treated by only supportive care or palliative treatment [4]. Moreover, troublesome symptoms related to local recurrence reduce the quality of life during surviving periods. Recent studies have reported that radical surgery with

\footnotetext{
* Correspondence: radiopiakim@hanmail.net

${ }^{1}$ Center for Colorectal Cancer, Research Institute and Hospital, National Cancer Center, Goyang, Korea

Full list of author information is available at the end of the article
}

microscopic curative resection presents a $48-60 \%$ longterm survival rate in patients surviving at 5 years [3,4,6-9]. These observations suggest that local control of LRRC is significantly associated with long-term survival and that the first goal of LRRC treatment should be local tumor control [5].

However, an aggressive approach with surgery alone also has severe weaknesses in that curative surgery is possible for only $20-30 \%$ of patients with locally recurrent rectal cancer (LRRC), because the intrapelvic space is too narrow to perform an R0 resection, and previous treatments, including surgery and radiotherapy, induce extensive fibrosis $[3,4]$. Moreover, high post-operative morbidities, of 30-60\% [6-8], and the non-operable state of some patients should also be considered in the clinical situation. To compensate for the shortage of radical surgery, chemoradiotherapy (CRT) with adjuvant or curative intent has a definitive role in improving the

\section{Biomed Central}


clinical outcome of patients with LRRC. Some studies have demonstrated that multimodal treatment including CRT results in better clinical outcomes, but the role and strategies for CRT have not yet been established. Thus, the purpose of the present study was to assess the clinical outcomes of CRT with or without surgery for patients with LRRC and to find useful and significant prognostic factors for the clinical situation.

\section{Methods}

\section{Patients}

This study was performed in accordance with the guidelines of our institutional review board. All patients provided written informed consent before salvage treatment.

Between January 2001 and February 2009, 67 patients with LRRC underwent CRT with or without surgery as a salvage treatment at the National Cancer Center (Goyang, Korea). Inclusion criteria were: (1) histologically confirmed primary rectal adenocarcinoma, (2) recurrent sites confined to the pelvic cavity, (3) no evidence of distant metastasis, and (4) salvage treatment with a curative aim.

Patient characteristics are shown in Table 1. The recurrence-free interval from the initial treatment of the primary tumor to locoregional recurrence ranged from 3 to 206 months (median, 22 months). Of 67 patients, 45 (67.2\%) presented with local recurrence after a sphincter-saving radical surgery to remove a primary tumor, 17 patients $(25.4 \%)$ developed recurrence following an abdominoperineal resection, and five patients (7.5\%) experienced recurrence following local excision. Fiftyfive patients $(82.1 \%)$ had a history of adjuvant chemotherapy for a primary tumor, and 23 (34.3\%) received adjuvant radiotherapy for a primary tumor. Symptoms related to local recurrence were sciatic pain in 17 patients, bowel habit changes in two patients, and a ureteral obstruction in one patient.

Through biopsy or surgical resection, 45 patients were confirmed histologically to have developed a local recurrence. In 22 patients, radiological evidence, including a positive positron-emission tomography (PET) scan or serial radiological examinations that showed progressive growth of the mass, were considered sufficient evidence to diagnose a local recurrence $[10,11]$. All patients were evaluated by digital rectal examination, a complete blood count, a liver function test, carcinoembryonic antigen (CEA) level, computed tomography (CT) of the chest and abdomino-pelvis, whole body PET, and magnetic resonance imaging (MRI) of the pelvis.

\section{Treatment}

Following the diagnosis of a locoregional recurrence, a surgeon, a medical oncologist, and a radiation oncologist
Table 1 Patient and treatment characteristics

\begin{tabular}{|c|c|}
\hline Characteristics & Value (\%) \\
\hline Median age, years (range) & $57(30-84)$ \\
\hline \multicolumn{2}{|l|}{ Gender } \\
\hline Male & $40(59.7)$ \\
\hline Female & $27(40.3)$ \\
\hline \multicolumn{2}{|l|}{ Stage at initial diagnosis } \\
\hline ypStage 0 & $3(4.2)$ \\
\hline pStage I/ypStage I & $5(7.0) / 1(1.4)$ \\
\hline pStage II/ypStage II & $14(19.7) / 3(4.2)$ \\
\hline pStage III/ypStage III & $21(29.6) / 8(11.3)$ \\
\hline pStage IV/ypStage IV & $6(8.5) / 1(1.4)$ \\
\hline pT1-2Nx & $5(7.0)$ \\
\hline \multicolumn{2}{|l|}{ Recurrence history } \\
\hline 0 & $51(76.1)$ \\
\hline 1 & $16(23.9)$ \\
\hline \multicolumn{2}{|l|}{ Symptoms at recurrence } \\
\hline Yes & $20(29.9)$ \\
\hline No & $47(70.1)$ \\
\hline \multicolumn{2}{|l|}{ Recurrent site } \\
\hline Central & $21(31.3)$ \\
\hline Lateral & $30(44.8)$ \\
\hline Posterior & $16(23.9)$ \\
\hline \multicolumn{2}{|l|}{ Pretreatment CEA } \\
\hline Normal $(\leq 5 \mathrm{ng} / \mathrm{mL})$ & $37(55.2)$ \\
\hline $\operatorname{High}(>5 \mathrm{ng} / \mathrm{mL}$ ) & $30(44.8)$ \\
\hline \multicolumn{2}{|l|}{ Salvage treatment } \\
\hline Surgery + CRT & $45(67.2)$ \\
\hline CRT alone & $22(32.8)$ \\
\hline \multicolumn{2}{|l|}{ Chemotherapy regimen } \\
\hline Fluoropyrimidine-alone & $35(52.2)$ \\
\hline Irinotecan or Oxaliplatin-based & $31(46.3)$ \\
\hline No & $1(1.5)$ \\
\hline \multicolumn{2}{|l|}{ Radicality of resection } \\
\hline RO & 19 (28.4) \\
\hline R1 & $24(35.8)$ \\
\hline R2 & $2(4.0)$ \\
\hline No surgery & $22(32.8)$ \\
\hline Median radiation dose, Gy (range) & $57.2(44.3-74.4)$ \\
\hline
\end{tabular}

Values in parentheses are percentages unless indicated otherwise. CRT chemoradiotherapy; R0, microscopically radical; R1, microscopically irradical; R2, macroscopically irradical; Gy, Gray; CEA, carcinoembryonic antigen.

reviewed the results of the diagnostic work-up to determine which treatment modality would be best suited for each patient. Considered unsuitable for curative surgery, 22 patients among 67 patients received definitive CRT without surgery. The other 45 underwent resection of a locally recurrent lesion with curative intent and preoperative $(n=3)$ or postoperative CRT $(n=42)$. Most adjuvant RT approaches consisted of post-operative, rather than pre-operative, as following reasons. (1) If a diagnosis is uncertain, histological confirm was possible through surgery. (2) If a patient has limitations for RT, 
such as previous RT history or small bowel adhesion at recurrence site, we performed omental flap transposition [12]. It functioned as spacer to increase a distance between small bowel and RT target area. (3) If RT target area and rectum are too close, we could perform protective colostomy for the prevention of RT-induced proctitis. (4) In some cases, preferences of doctor and patient were cause of such practice.

Radiotherapy was administered using three-dimensional conformal radiation $(n=60)$, proton beam therapy $(n=4)$, or helical tomotherapy $(n=3)$. All patients underwent a $\mathrm{CT}$ simulation in the treatment position, which was generally prone. The gross tumor volume, consisting of all detectable tumors, was determined from the CT, PET, and MRI data. The clinical target volume covered the gross tumor volume, tumor bed, and other suspicious microscopic lesions. The initial planning target volume included the clinical target volume plus a $10-20 \mathrm{~mm}$ margin. Organs at risk were also delineated, including the spinal cord, bladder, both kidneys, and the small bowel.

The radiation dose was 45-72 Gy, with fraction sizes of 1.8-3.0 Gy (biologically equivalent dose in 2-Gy fractions $\left[\mathrm{BED}_{2 \mathrm{~Gy}}\right]$ using a linear quadratic model, and the $\alpha / \beta$; ratio was 10 for acute effects on normal tissues and tumors: 44.3-74.4 $\mathrm{BED}_{2 \mathrm{~Gy}}$ ), and the median dose was 57.2 $\mathrm{BED}_{2 \mathrm{~Gy}}$. The dose-fractionation schedules were as follows: $1.8 \mathrm{~Gy} /$ fraction in 60 patients, $2.4 \mathrm{~Gy} /$ fraction in four patients, $2.7 \mathrm{~Gy} /$ fraction in one patient, $2.8 \mathrm{~Gy} /$ fraction in one patient, and a $3 \mathrm{~Gy} /$ fraction in one patient. The radiation dose was adjusted according to the status of the residual tumor, radiation history, and proximity to the small bowel.

Most patients underwent concurrent chemotherapy with radiation, consisting of a fluoropyrimidine $(n=35)$, irinotecan, or oxaliplatin-based regimens $(n=31)$. Only one patient could not receive chemotherapy, because of hepatitis. Maintenance chemotherapy after concurrent CRT was applied to $88.1 \%$ of patients $(n=59)$, which consisted of a fluoropyrimidine regimen $(n=23)$ and an irinotecan or oxaliplatin-based regimen $(n=36)$. The remaining eight patients did not undergo maintenance chemotherapy because of patient refusal $(n=6)$ or poor performance status $(n=2)$.

\section{Evaluation}

After salvage treatment, follow-up was performed every 3 months for the first 2 post-treatment years and every 6 months thereafter. Follow-up evaluations included a physical examination, digital rectal examination, complete blood count, liver function test, and serum CEA level at each visit. Chest radiography and CT scanning of the abdomen and pelvis were performed every 6 months after salvage treatment. Relapse after salvage treatment was confirmed pathologically by direct biopsy or cytology, and/or radiographical evidence. Locoregional failure was defined as a new lesion or disease progression within the pelvic cavity, and distant failure as any recurrence outside the pelvic cavity.

\section{Statistical Analyses}

Overall survival (OS), relapse-free survival (RFS), locoregional relapse-free survival (LRFS), and distant metastasis-free survival (DMFS) were calculated as the interval from the first date of salvage treatment to the date of death, any relapse detection, locoregional relapse detection, or distant metastasis detection, respectively.

Survival curves were generated by the Kaplan-Meier method, and a univariate survival comparison was performed using the log-rank test. Multivariate analyses were conducted with the Cox proportional hazards model and the backward stepwise selection procedure. The chi-squared, Fisher's exact, and $t$-tests were performed to compare various parameters between different treatment groups. A p-value of $<0.05$ was considered to indicate statistical significance.

\section{Results}

\section{Survival and pattern of failure}

The median follow-up time for living patients was 41 months (range, 16-108). The median OS of all patients was 59 months. Median RFS, LRFS, and DMFS were 18, not reached, and 23 months, respectively. Five-year OS, RFS, LRFS, and DMFS were $48.9 \%, 31.6 \%, 66.4 \%$, and $40.6 \%$, respectively. A relapse after salvage treatment occurred in 41 (61.2\%) patients during the follow-up period, and locoregional failure was detected in six patients $(9.0 \%)$, distant metastasis in 30 patients $(44.8 \%)$, and both failures in five patients (7.5\%). During followup period, severe G-I complication over Grade III, associated with CRT, did not occur.

\section{Analysis of prognostic factors}

The univariate analysis of the effect of prognostic factors on clinical outcome is shown in Table 2. The presence of symptoms was a significant prognostic factor correlated with poor OS $(\mathrm{p}=0.025)$, RFS $(\mathrm{p}=0.007)$, LRFS $(\mathrm{p}=0.003)$, and DMFS $(\mathrm{p}=0.047)$. In contrast, age, gender, type of primary surgery, recurrence-free interval, recurrence history, recurrence site, pre-treatment CEA serum level, salvage treatment, chemotherapy regimen, resection margin, and radiation dose had no statistically significant effect on OS, RFS, LFS, or DMFS. In the multivariate analysis, the presence of symptoms was an independent prognostic factor predicting poor OS $(\mathrm{p}=$ 0.025; hazard ratio [HR], 3.46; 95\% confidence interval [CI], 1.17-10.22), RFS ( $\mathrm{p}=0.017 ; \mathrm{HR}, 3.04 ; 95 \% \mathrm{CI}$, $1.22-7.59)$, LRFS ( $p=0.005$; HR, 3.60; $95 \%$ CI, 1.48 - 
Table 2 Univariate analysis of factors affecting clinical outcome

\begin{tabular}{|c|c|c|c|c|c|c|c|c|}
\hline & $5 y$ OS & $\mathrm{pt}$ & 5y RFS & $\mathrm{pt}$ & 5y LRFS & $\mathrm{pt}$ & 5y DMFS & $\mathrm{pt}$ \\
\hline \multicolumn{9}{|l|}{ Age (years) } \\
\hline$<60$ & 50.5 & .653 & 27.6 & .547 & 57.6 & .084 & & \\
\hline$\geq 60$ & 47.9 & & 36.2 & & 75.9 & & & \\
\hline \multicolumn{9}{|l|}{ Gender } \\
\hline Male & 55.6 & .381 & 34.8 & .340 & 73.7 & .141 & 42.3 & .811 \\
\hline Female & 34.9 & & 27.7 & & 55.7 & & 38.1 & \\
\hline \multicolumn{9}{|l|}{ Recurrence-free interval (months) } \\
\hline$<24$ & 46.4 & .675 & 33.2 & .473 & 59.8 & .248 & 40.6 & .663 \\
\hline$\geq 24$ & 50.7 & & 26.9 & & 72.9 & & 38.5 & \\
\hline \multicolumn{9}{|l|}{ Previous recurrence history } \\
\hline 0 & 51.2 & .417 & 36.4 & .061 & 66.9 & .834 & 43.0 & .420 \\
\hline 1 & 38.8 & & 16.7 & & 65.2 & & 33.0 & \\
\hline \multicolumn{9}{|l|}{ Symptoms at recurrence } \\
\hline Yes & 26.3 & .025 & 20.0 & .007 & 40.0 & .003 & 25.8 & .047 \\
\hline No & 58.4 & & 38.3 & & 76.2 & & 47.2 & \\
\hline \multicolumn{9}{|l|}{ Recurrence site } \\
\hline Central & 56.0 & .494 & 43.5 & .429 & 67.7 & .918 & 54.2 & .305 \\
\hline Lateral & 44.8 & & 26.0 & & 69.1 & & 31.5 & \\
\hline posterior & 36.4 & & 35.3 & & 63.5 & & 36.2 & \\
\hline \multicolumn{9}{|l|}{ Pretreatment CEA (ng/mL) } \\
\hline$\leq 5$ & 45.7 & .882 & 41.8 & .071 & 72.1 & .154 & 49.2 & .458 \\
\hline$>5$ & 52.8 & & 21.8 & & 59.1 & & 33.8 & \\
\hline \multicolumn{9}{|l|}{ Salvage Treatment } \\
\hline Surgery + CRT & 52.8 & .181 & 35.2 & .113 & 71.0 & .379 & 43.6 & .335 \\
\hline CRT alone & 40.6 & & 24.5 & & 55.9 & & 34.6 & \\
\hline \multicolumn{9}{|l|}{ Chemotherapy regimen } \\
\hline Fluoropyrimidines-alone & 47.3 & .910 & 36.7 & .572 & 67.2 & .720 & 42.9 & .562 \\
\hline Irinotecan or Oxaliplatin -based & 41.0 & & 22.0 & & 64.7 & & 33.8 & \\
\hline \multicolumn{9}{|l|}{ Resection§ } \\
\hline RO & 60.4 & .994 & 35.1 & .956 & 77.7 & .529 & 37.6 & .919 \\
\hline $\mathrm{R} 1$ or R2 & 42.9 & & 34.3 & & 65.6 & & 46.8 & \\
\hline \multicolumn{9}{|l|}{ Radiation dose $\left(\mathrm{BED}_{2 \mathrm{~Gy}}\right)$} \\
\hline$<60$ & 46.9 & .607 & 32.3 & .281 & 78.2 & .065 & 41.0 & .694 \\
\hline$\geq 60$ & 48.3 & & 29.2 & & 52.9 & & 39.2 & \\
\hline
\end{tabular}

*values are percentages of patients; †log rank test. OS, overall survival; § Among 45 patients undergoing surgical resection; RFS, recurrence-free survival; LRFS, locoregional relapse free survival; DMFS, distant metastasis-free survival; CRT, chemoradiotherapy; R0, microscopically radical; R1, microscopically irradical; R2, macroscopically irradical; $B_{2 E D_{2 y}}$, biologically equivalent dose in 2 -Gy fractions using a linear quadratic model, and the $\alpha / \beta$ ratio was 10 for acute effects on normal tissues and tumors. CEA, carcinoembryonic antigen.

8.80), and DMFS ( $\mathrm{p}=0.032$; HR, 2.93; 95\% CI, 1.10 7.89).

\section{Comparison between CRT with and without surgery}

No statistically significant difference was found in OS ( $\mathrm{p}$ $=0.181)$, RFS $(p=0.113)$, LRFS $(p=0.379)$, or DMFS $(\mathrm{p}=0.458)$ when clinical outcomes were compared between the CRT with surgery and definitive CRT without surgery groups. Figure 1 shows the OS and RFS curves for each group. The prognostic factors, as described above, were stratified by the two groups and are shown in Table 3. Significantly more patients with symptoms and an abnormal CEA level $(>5 \mathrm{ng} / \mathrm{mL})$ received definitive CRT without surgery $(\mathrm{p}=0.014$, 0.009 , respectively). The mean radiation dose was 54.6 $\mathrm{BED}_{2 \mathrm{~Gy}}$ in the CRT with surgery group, and 66.5 $\mathrm{BED}_{2 \mathrm{~Gy}}$ in the definitive CRT without surgery group ( $\mathrm{p}$ $<0.001$ ). In addition, post-operative RT dose was also different according to margins status. Patients with a positive resection margin received the higher radiation dose (mean dose, 57.5 BED2Gy) than patients with a negative resection margin (mean dose, 50.6 BED2Gy).

\section{Discussion}

This study assessed whether CRT with or without surgery was effective in patients with LRRC and identified 
A

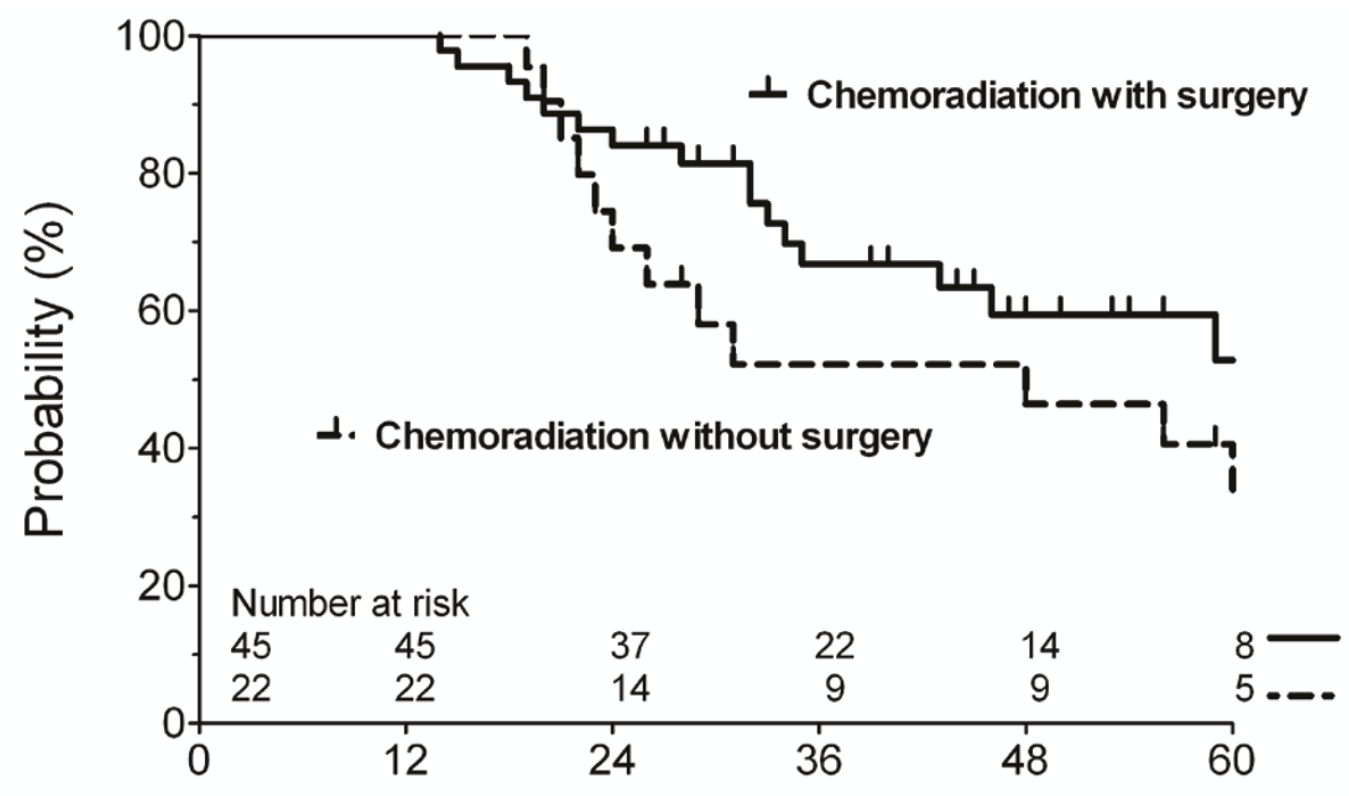

Months

B

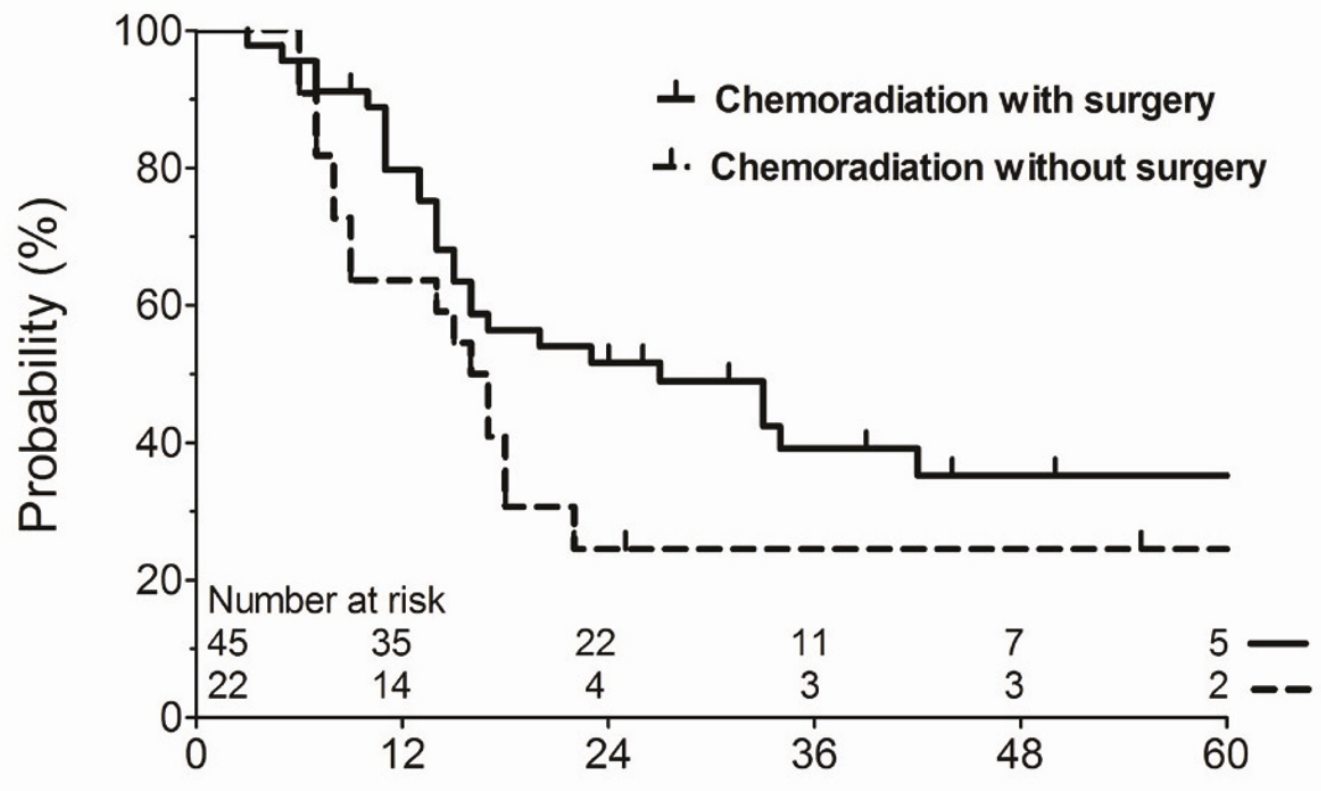

Months

Figure 1 Overall survival (a) and relapse-free survival (b) between the chemoradiotherapy with surgery and without surgery groups.

useful prognostic factors for the clinical setting. A 5year OS of $48.9 \%$ and a LRFS of $66.4 \%$ was achieved; this outcome was better than previous multimodal treatment reports (5-yr OS of $25-36 \%$, LRFS of $40-50 \%$ ).
However, DMFS was similar to the results of previous studies and was approximately 40-50\% [6-8,13-15]. When evaluating prognostic factors, symptoms related to LRRC have a significant effect on OS, RFS, LRFS, and 
Table 3 Patient characteristics between the surgery plus chemoradiation and chemoradiation alone groups

\begin{tabular}{|c|c|c|c|}
\hline Characteristic & $\begin{array}{c}\text { Surgery }+ \\
\text { chemoradiation } \\
(n=45)\end{array}$ & $\begin{array}{c}\text { chemoradiation } \\
(n=22)\end{array}$ & $P$ \\
\hline Mean age, years & $56.7 \pm 11.5$ & $60.0 \pm 13.4$ & $0.377 \S$ \\
\hline \multicolumn{4}{|l|}{ Gender } \\
\hline Male & 25 & 15 & $0.322+$ \\
\hline Female & 20 & 7 & \\
\hline $\begin{array}{l}\text { Recurrence-free } \\
\text { interval, months }\end{array}$ & 35.3 & 30.0 & $0.521 \S$ \\
\hline \multicolumn{4}{|l|}{ Chemotherapy history } \\
\hline Yes & 35 & 20 & $0.310 \neq$ \\
\hline No & 10 & 2 & \\
\hline \multicolumn{4}{|l|}{ Radiation history } \\
\hline Yes & 14 & 6 & $0.747 \dagger$ \\
\hline No & 31 & 16 & \\
\hline \multicolumn{4}{|l|}{ Recurrence history } \\
\hline 0 & 35 & 16 & $0.649+$ \\
\hline 1 & 10 & 6 & \\
\hline \multicolumn{4}{|l|}{$\begin{array}{l}\text { Symptoms at } \\
\text { recurrence }\end{array}$} \\
\hline Yes & 9 & 11 & $0.014 \dagger$ \\
\hline no & 36 & 11 & \\
\hline \multicolumn{4}{|l|}{ Recurrence site } \\
\hline Central & 16 & 5 & $0.440+$ \\
\hline Lateral & 20 & 10 & \\
\hline posterior & 9 & 7 & \\
\hline \multicolumn{4}{|l|}{$\begin{array}{l}\text { Pretreatment CEA (ng/ } \\
\mathrm{mL} \text { ) }\end{array}$} \\
\hline$\leq 5$ & 30 & 7 & $0.009+$ \\
\hline$>5$ & 15 & 15 & \\
\hline \multicolumn{4}{|l|}{$\begin{array}{l}\text { Chemotherapy } \\
\text { regimen }\end{array}$} \\
\hline $\begin{array}{l}\text { Fluoropyrimidines } \\
\text { alone }\end{array}$ & 21 & 13 & $0.249+$ \\
\hline $\begin{array}{l}\text { Irinotecan or } \\
\text { oxaliplatin-based }\end{array}$ & 24 & 8 & \\
\hline \multicolumn{4}{|l|}{$\begin{array}{l}\text { Radiation dose } \\
\left(\mathrm{BED}_{2 \mathrm{~Gy}}\right)\end{array}$} \\
\hline$<60$ & 34 & 1 & $<0.001 \dagger$ \\
\hline$\geq 60$ & 11 & 21 & \\
\hline $\begin{array}{l}\text { Mean radiation dose, } \\
\mathrm{BED}_{2 \mathrm{~Gy}}\end{array}$ & $54.6 \pm 5.5$ & $66.5 \pm 6.2$ & $<0.001 \S$ \\
\hline
\end{tabular}

tchi-squared test; \# Fisher exact test; $\S \mathrm{t}$-test; $\mathrm{BED}_{2 \mathrm{~Gy}}$, biologically equivalent dose in 2-Gy fractions using a linear quadratic model, CEA, carcinoembryonic antigen; and the $\alpha / \beta$; ratio was 10 for acute effects on normal tissues and tumors.

DMFS. Pretreatment quality of life could be related to the clinical outcomes for many kinds of cancer and could be considered a potential prognostic factor. In other studies, symptoms related to LRRC have been reported as significant prognostic factors for a poor outcome $[6,7,13]$ and such patients are considered a low possibility for radical resection [13]. Hydronephrosis presenting in two patients indicated a lower chance for obtaining a negative resection margin [16]. LRRC symptoms are a useful and readily assessable prognostic factor in the clinical setting.

Another strength of the present study was that CRT was tailored to the individual risk of a residual tumor and the potential risk of a complication after an attempt at curative resection. The patients in the LRRC group were actually heterogeneous when considering resectability, the strongest factor affecting clinical outcome. Tumor location and the degree of local invasion affect resectability, and the posterior and lateral location, particularly including a sacral, ureteral, or iliac vessel invasion, are almost unresectable and cause marked postoperative disability $[10,17]$. Many studies on multimodal LRRC treatment have attempted preoperative CRT to solve the problem of low resectability [6-9,13,18-20], and one of those studies demonstrated significantly increased resectability [6]. However, resectability improved by preoperative CRT was still insufficient, at $30-60 \%[6-8,13,15,18,21]$. The remaining $40-$ $70 \%$ of patients with incompletely resected LRRC showed disappointing local control (30\% 3-year LRFS), and this insufficient local control lead to a poor survival outcome of $10-16 \%$ for the 5-year OS $[6,8]$. Moreover, the pre-operative CRT radiation dose was a uniform low dose of 30-50 Gy, but did not consider the risk of an unresectable or residual tumor. When local control is the prime goal of LRRC treatment, the radiation dose or CRT plan should be determined based on such risks for local failure and complication.

All patients, except three who underwent preoperative CRT followed by radical resection, received CRT with an adjusted postoperative or definitive radiation dose, based on the risk for local failure and complication. In the preoperative evaluation, poor surgical candidates who were definitively unresectable or medically inoperable underwent definitive CRT with a high radiation dose (mean dose, $66.5 \mathrm{BED}_{2 \mathrm{~Gy}}$ ). In patients with a positive resection margin, the post-operative radiation dose (mean dose, $57.5 \mathrm{BED}_{2 \mathrm{~Gy}}$ ) was also higher than in patients with a negative resection margin (mean dose, $50.6 \mathrm{BED}_{2 \mathrm{~Gy}}$ ). Some studies have demonstrated that a higher radiation dose for patients with LRRC is correlated with better clinical outcome [6,20]. Fifteen patients underwent omental flap transposition as a spacer, as proposed by Kim et al. [12] and seven patients received proton beam or helical tomotherapy to safely deliver a high dose of radiation to recurrent sites in patients who had previously undergone radiation and whose small bowel is very close to the target area. The radiation plan also focused on risky areas for local failure, referring to operative findings and pathological reports. As a result, this study showed improved local control, leading to improved OS. Moreover, patients with a positive 
resection margin demonstrated notably better outcomes (5-year OS, $42.9 \%$ ) than other studies $[6,7,13]$. This study showed that the purpose of CRT should not be just adjuvant, aimed at increasing resectability, but an aggressive curative local control, similar to surgery. Such a treatment plan could result in an increased cure rate with long-term survival.

The present study also showed that definitive CRT with a high radiation dose (mean dose, $66.5 \mathrm{BED}_{2 \mathrm{~Gy}}$ ) may be a potentially curative option for long-term survival (5-year OS, 48.9\%). The actuarial 5-year OS, RFS, LRFS, and DMFS for definitive CRT was not significantly different than CRT with surgery. However, median OS, RFS, LRFS, and DMFS for definitive CRT tended to be slightly inferior to the surgery group, but this difference was not statistically significant. Patients with an abnormal CEA level or the presence of symptoms occurred more in the definitive CRT group, and this may have affected the outcome of the definitive CRT group. Symptoms were a significant prognostic factor in the present study and CEA level has been reported as a significant prognostic factor in some previous studies $[22,23]$. Although definitive CRT cannot substitute for radical surgery, it can be an option aimed at a cure with long-term survival for a fair number of patients with an inoperable medical condition or an unresectable lesion.

The present study has some limitations. First, in contrast to other studies, the radicality of resection was not a significant prognostic factor predicting survival outcome or tumor control. It might be related with low statistical power due to small sample size $(n=67)$. In addition, the reason could be also that radiation dose was increased according to residual tumor status. Such a difference in the radiation dose appeared to dilute the effect of surgical radicality. Another reason could be that a relatively small proportion of R2 resections (4\%) of the CRT with surgery might induce improvement in the group with positive resection margin. Patients with expected unresectability from the radiological evaluation were recommended for definitive CRT without surgery, so a $\mathrm{R} 2$ resection might have been rarer than in other studies. In that $\mathrm{R} 2$ resection have more effect on an unfavorable clinical outcome than R1 resection [24], the effect of radicality might fail to get the statistical significance. Second, we could observe tendency in the survival curves that the CRT with surgery got the slightly more favorable outcome than the definitive CRT group, but it failed to get a statistical significance. This could be resulted from the effects of a small sample size, surgical morbidities, and the differences of radiation dose. This study showed the possibility of a definitive CRT for cure, but further study with a larger sample size is needed for a definitive conclusion about the comparison between the two groups. Third, we had a heterogeneous population undergoing different CRT approaches and chemotherapy regimens. Accordingly, further larger scale and prospective studies with additional long-term follow-up are needed to compare different CRT approaches definitively.

\section{Conclusions}

Our study demonstrated that LRRC has the potential to be cured with CRT with or without surgery, and the symptoms related to LRRC are a significant prognostic factor predicting poor clinical outcome. The CRT approach should focus on local control; thus, individualized CRT strategies are recommended, based on the possibility of resectability and risk of local failure. Thus, CRT with an adjusted radiation dose is a potential curative option for LRRC, including definitive CRT without surgery.

\section{Acknowledgements}

This work was supported by a National Cancer Center Grant (NCC-1010480 \& 0910010).

\section{Author details}

${ }^{1}$ Center for Colorectal Cancer, Research Institute and Hospital, National Cancer Center, Goyang, Korea. ${ }^{2}$ Department of Radiation Oncology, Seoul National University College of Medicine, Seoul, Korea. ${ }^{3}$ Department of Radiation Oncology, Chung-Ang University College of Medicine, Seoul, Korea.

\section{Authors' contributions}

DYK contributed to conception and design of the study, and revised the manuscript. JHL, SYK, JWP, and THK contributed to analysis and interpretation of data, and drafted the manuscript. HJC, HSC participated in revising the manuscript. $\mathrm{HO}$ participated in data acquisition and literature research. SWP contributed to conception of the study. All authors read and approved the final manuscript.

\section{Competing interests}

The authors declare that they have no competing interests.

Received: 16 February 2011 Accepted: 20 May 2011

Published: 20 May 2011

\section{References}

1. Colorectal Cancer Collaborative Group: Adjuvant radiotherapy for rectal cancer: a systematic overview of 8,507 patients from 22 randomised trials. Lancet 2001, 358:1291-1304

2. Heald RJ, Moran BJ, Ryall RD, Sexton R, MacFarlane JK: Rectal cancer: the Basingstoke experience of total mesorectal excision, 1978-1997. Arch Surg 1998, 133:894-899.

3. Bakx R, Visser O, Josso J, Meijer S, Slors JF, van Lanschot JJ: Management of recurrent rectal cancer: a population based study in greater Amsterdam. World J Gastroenterol 2008, 14:6018-6023.

4. Palmer G, Martling A, Cedermark B, Holm T: A population-based study on the management and outcome in patients with locally recurrent rectal cancer. Ann Surg Oncol 2007, 14:447-454.

5. Kim TH, Chang HJ, Kim DY, Jung KH, Hong YS, Kim SY, Park JW, Oh JH, Lim SB, Choi HS, Jeong SY: Pathologic nodal classification is the most discriminating prognostic factor for disease-free survival in rectal cancer patients treated with preoperative chemoradiotherapy and curative resection. Int J Radiat Oncol Biol Phys 2010, 77:1158-1165.

6. Dresen RC, Gosens MJ, Martijn H, Nieuwenhuijzen GA, Creemers GJ, DanielsGooszen AW, van den Brule AJ, van den Berg HA, Rutten HJ: Radical 
resection after IORT-containing multimodality treatment is the most important determinant for outcome in patients treated for locally recurrent rectal cancer. Ann Surg Oncol 2008, 15:1937-1947.

7. Hahnloser D, Nelson H, Gunderson LL, Hassan I, Haddock MG, O'Connell MJ, Cha S, Sargent DJ, Horgan A: Curative potential of multimodality therapy for locally recurrent rectal cancer. Ann Surg 2003, 237:502-508.

8. Heriot AG, Byrne CM, Lee P, Dobbs B, Tilney H, Solomon MJ, Mackay J, Frizelle F: Extended radical resection: the choice for locally recurrent rectal cancer. Dis Colon Rectum 2008, 51:284-291.

9. Kusters M, Dresen RC, Martijn H, Nieuwenhuijzen GA, van de Velde CJ, van den Berg HA, Beets-Tan RG, Rutten HJ: Radicality of resection and survival after multimodality treatment is influenced by subsite of locally recurrent rectal cancer. Int J Radiat Oncol Biol Phys 2009, 75:1444-1449.

10. Bouchard P, Efron J: Management of recurrent rectal cancer. Ann Surg Oncol 2010, 17:1343-1356.

11. Watson AJ, Lolohea S, Robertson GM, Frizelle FA: The role of positron emission tomography in the management of recurrent colorectal cancer: a review. Dis Colon Rectum 2007, 50:102-114.

12. Kim TH, Kim DY, Jung KH, Hong YS, Kim SY, Park JW, Lim SB, Choi HS, Jeong SY, Oh JH: The role of omental flap transposition in patients with locoregional recurrent rectal cancer treated with reirradiation. J Surg Oncol 2010, 102:789-95.

13. Pacelli F, Tortorelli AP, Rosa F, Bossola M, Sanchez AM, Papa V, Valentini V, Doglietto GB: Locally recurrent rectal cancer: prognostic factors and long-term outcomes of multimodal therapy. Ann Surg Oncol 2010, 17:152-162.

14. Wiig JN, Larsen SG, Giercksky KE: Operative treatment of locally recurrent rectal cancer. Recent Results Cancer Res 2005, 165:136-147.

15. Valentini V, Morganti AG, Gambacorta MA, Mohiuddin M, Doglietto GB, Coco C, De Paoli A, Rossi C, Di Russo A, Valvo F, Bolzicco G, Dalla Palma M, Study Group for Therapies of Rectal Malignancies (STORM): Preoperative hyperfractionated chemoradiation for locally recurrent rectal cancer in patients previously irradiated to the pelvis: A multicentric phase II study. Int J Radiat Oncol Biol Phys 2006, 64:1129-1139.

16. Larsen SG, Wiig JN, Giercksky KE: Hydronephrosis as a prognostic factor in pelvic recurrence from rectal and colon carcinomas. Am J Surg 2005, 190:55-60.

17. Park JK, Kim YW, Hur H, Kim NK, Min BS, Sohn SK, Choi YD, Kim YT, Ahn JB, Roh JK, Keum KC, Seong JS: Prognostic factors affecting oncologic outcomes in patients with locally recurrent rectal cancer: impact of patterns of pelvic recurrence on curative resection. Langenbecks Arch Surg 2009, 394:71-77.

18. Wiig JN, Tveit KM, Poulsen JP, Olsen DR, Giercksky KE: Preoperative irradiation and surgery for recurrent rectal cancer. Will intraoperative radiotherapy (IORT) be of additional benefit? A prospective study. Radiother Oncol 2002, 62:207-213.

19. Saito N, Koda K, Takiguchi N, Oda K, Ono M, Sugito M, Kawashima K, Ito M: Curative surgery for local pelvic recurrence of rectal cancer. Dig Surg 2003, 20:192-199.

20. Mohiuddin M, Marks G, Marks J: Long-term results of reirradiation for patients with recurrent rectal carcinoma. Cancer 2002, 95:1144-1150.

21. Schurr P, Lentz E, Block S, Kaifi J, Kleinhans H, Cataldegirmen G, Kutup A, Schneider C, Strate T, Yekebas E, lzbicki J: Radical redo surgery for local rectal cancer recurrence improves overall survival: a single center experience. J Gastrointest Surg 2008, 12:1232-1238.

22. Asoglu O, Karanlik H, Muslumanoglu M, Igci A, Emek E, Ozmen V, Kecer M, Parlak M, Kapran Y: Prognostic and predictive factors after surgical treatment for locally recurrent rectal cancer: a single institute experience. Eur J Surg Oncol 2007, 33:1199-1206.

23. Bedrosian I, Giacco G, Pederson L, Rodriguez-Bigas MA, Feig B, Hunt KK, Ellis L, Curley SA, Vauthey JN, Delclos M, Crane CH, Janjan N, Skibber JM: Outcome after curative resection for locally recurrent rectal cancer. Dis Colon Rectum 2006, 49:175-182.

24. Suzuki K, Gunderson LL, Devine RM, Weaver AL, Dozois RR, Istrup DM, Martenson JA, O'Connell MJ: Intraoperative irradiation after palliative surgery for locally recurrent rectal cancer. Cancer 1995, 75:939-952.

doi:10.1186/1748-717X-6-51

Cite this article as: Lee et al: Clinical outcomes of chemoradiotherapy for locally recurrent rectal cancer. Radiation Oncology 2011 6:51.

\section{Submit your next manuscript to BioMed Central and take full advantage of:}

- Convenient online submission

- Thorough peer review

- No space constraints or color figure charges

- Immediate publication on acceptance

- Inclusion in PubMed, CAS, Scopus and Google Scholar

- Research which is freely available for redistribution 